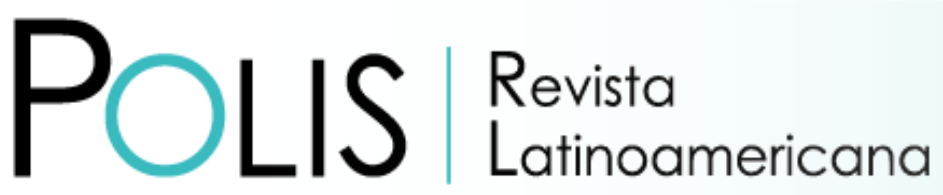

V20 | N60 | 2021

DOI: $10.32735 /$ S0718-6568/2021-N60-1655

\title{
De experiencias de solidaridad a la politización en la precariedad: mujeres migrantes y organización social en tiempos de "estallido" y pandemia"
}

\author{
María Fernanda Stang Alva \\ Centro de Investigación en Ciencias Sociales y Juventud (CISJU) \\ Universidad Católica Silva Henríquez, Santiago, Chile \\ Email: fstang@ucsh.cl
}

Recibido: 13.06.2021 | Aceptado: 02.08.2021

\begin{abstract}
Resumen: El artículo se propone describir y reflexionar sobre el modo en que, frente al "estallido social" chileno y la pandemia por Covid-19 en el país, se desplegaron experiencias reticulares de solidaridad que vinculan a migrantes, principalmente mujeres, con actores nacionales. Tales experiencias, en algunos casos, se articularon a procesos de subjetivación política de estas migrantes, intensificándolos incluso. Esas subjetivaciones políticas construyen un sujeto que se enuncia a partir de la desigualdad de clase en la formación social del capitalismo neoliberal, y la desigualdad que instituye el Estado-nación entre ciudadano y no ciudadano. Por esa razón, estos procesos son potencialmente transformadores de las ideas y prácticas ligadas a la ciudadanía. El análisis se realiza a propósito de cuatro experiencias de solidaridad organizada: dos de ellas relacionadas a redes de ayuda de trabajadoras sexuales y trabajadoras nocturnas, y otras dos surgidas en torno a luchas por la vivienda, situadas en las dos comunas del país con mayor cantidad de migrantes internacionales: Santiago y Antofagasta.
\end{abstract}

Palabras clave: Subjetivación política; luchas de migración; nuevas ciudadanías, organización social.

\section{From Experiences of Solidarity to the Politicization in Precariousness: Migrant Women and Social Organization in an era of "Uprise" and Pandemic}

\begin{abstract}
The article aims to describe and reflect on the way in which, in the face of the Chilean "social outbreak" and the Covid-19 pandemic in the country, network experiences of solidarity were deployed that link migrants, mainly women, with national actors. In some cases, such experiences were linked to processes of political subjectivation of these migrants, at times even intensifying them. These political subjectifications construct a subject that is enunciated from the class inequality inherent in neoliberal capitalism, and inequality that the nation-state establishes between citizens and non-citizens. For this reason, these processes are potentially transformative of the ideas and practices linked to citizenship. The analysis is carried out with regard to four experiences of organized solidarity: two of them related to help networks of sex and nocturnal workers, and another two that arose around struggles for housing, located in the two municipalities of the country with the largest number of of international migrants: Santiago and Antofagasta.
\end{abstract}

1 A lo largo de este artículo, y para ajustarse a las usuales normas de estilo del registro de escritura académico, se utiliza distinción binaria o/a, a sabiendas de su insuficiencia para dar cuenta de la diversidad de géneros existente. 
Keywords: Political subjectivation; migration struggles; new citizenships, social organization.

\title{
Das experiências de solidariedade à politização na precariedade: mul- heres migrantes e organização social em tempos de "explosão social" e pandemia
}

\begin{abstract}
Resumo: $O$ artigo tem como objetivo descrever e refletir sobre a forma como, em face da "explosão social" chilena e da pandemia de Covid-19 no país, se implantaram experiências solidárias em rede que vinculam os migrantes, principalmente mulheres, aos atores nacionais. Tais experiências, em alguns casos, estiveram vinculadas a processos de subjetivação política desses migrantes, inclusive intensificando-os. Essas subjetivações políticas constroem um sujeito que se enuncia a partir da desigualdade de classes na formação social do capitalismo neoliberal e da desigualdade que o Estado-nação estabelece entre cidadão e não cidadão. Por isso, esses processos são potencialmente transformadores das ideias e práticas vinculadas à cidadania. A análise é feita a respeito de quatro experiências de solidariedade organizada: duas delas relacionadas com redes de ajuda a profissionais do sexo e noturnas, e outras duas que surgiram em torno de lutas por moradia, localizadas nas duas comunas do país com maior número de migrantes internacionais: Santiago e Antofagasta.
\end{abstract}

Palavras-chave: Subjetivação política; lutas de migração; novas cidadanias, organização social.

\section{Como citar este artículo:}

Stang Alva, M. (2021). De experiencias de solidaridad a la politización en la precariedad: mujeres migrantes y organización social en tiempos de "estallido" y pandemia. Polis Revista Latinoamericana, 20 (60), 47-67. doi: http://dx.doi.org/10.32735/S0718-6568/2021-N60-1655

\section{Introducción}

"La representación de los inmigrantes como actores políticos es rara, si no inexistente", dice Liliana Suárez Navaz (2007), una autora que ha investigado las luchas de los "sin papeles" en España durante la década de 2000. Abdelmalek Sayad, por su parte, habló de una ilusión de neutralidad política del/la migrante y de la migración, "cuya naturaleza intrínsecamente política es enmascarada, cuando no es negada, en provecho de su única función económica" (Sayad, 1998, p. 19, traducción propia); "[l]a estadía autorizada del inmigrante está enteramente sujeta al trabajo, única razón de ser que le es reconocida" (Sayad, 1998, p. 55, traducción propia), afirma el autor. Esta unidimensionalización del sujeto migrante (Stang, 2009), ligada a la construcción de la extranjeridad como una forma de precarización del trabajo en la economía global, junto al anclaje Estado-nacionalizante de la concepción tradicional de ciudadanía (Velasco, 2016), tienen implicancias directas en las posibilidades del o la migrante internacional de constituirse como sujeto político en la sociedad receptora; aun así, esa subjetivación política es indisimulable, y ha tenido materializaciones episódicas históricas².

2 Por ejemplo, la "huelga de los inquilinos" en Argentina, en 1907 (Domenech, 2015; en línea, https://www.youtube.com/watch? $v=O o e r V K l y W g E)$, o las "huelgas de alquileres" en Francia, iniciadas en 1970 y que se extendieron por más de 10 años (Morice, 2007). 
El tema que se aborda en este artículo se ubica en este campo de discusión, en la medida que se propone describir y reflexionar sobre el modo en que, frente a dos contingencias o acontecimientos -el denominado "estallido social" que se produjo en Chile desde octubre de 2019, y la pandemia ocasionada por el virus Covid-19, que se inició en el país en marzo de 2020-, se desplegaron ciertas prácticas de solidaridad organizada-vinculando a migrantes, principalmente mujeres, con actores nacionales- que, en algunos casos, se articularon a procesos de subjetivación política de estas migrantes -intensificándolos incluso-, potencialmente transformadores de las ideas y prácticas ligadas a la ciudadanía. En ese sentido, este trabajo se inscribe -según la sistematización que realiza Perissinotti (2016)- en el sub-campo de estudio de las prácticas políticas migrantes, dentro de la línea de las exploraciones sobre los procesos de organización de migrantes que demandan a los Estados de destino su reconocimiento como sujetos de derechos (jurídicos, sociales y políticos) ${ }^{3}$.

El análisis se realiza a propósito de cuatro experiencias de solidaridad organizada frente a uno o ambos acontecimientos, dos de ellas relacionadas a redes de ayuda de trabajadoras sexuales y trabajadoras nocturnas, y otras dos surgidas en torno a luchas por la vivienda, situadas en las dos comunas chilenas con mayor cantidad de migrantes internacionales según el último censo nacional (2017): Santiago, la capital, y Antofagasta, en el norte del país ${ }^{4}$.

\section{La caja de herramientas conceptuales}

Para el análisis de las experiencias de las que se ocupa el artículo se consideran dos nociones principalmente: la de subjetivación política, entendida a partir de los aportes de Jacques Rancière (2006), que ha mostrado ser heurísticamente productiva para pensar procesos de politización de personas migrantes en diferentes escenarios (por ejemplo: Franzé, 2010; Martínez Bonora, 2012), y la de luchas de migración, en una reapropiación de varias propuestas de definición -y variantes de denominación-.

Rancière define lo político, por una parte, como "el terreno del encuentro entre la política y la policía en el tratamiento de un daño" (Rancière, 2006, p. 18), y el proceso de subjetivación, por la otra, como "la formación de un uno que no es un sí, sino la relación de un sí con otro" (Rancière, 2006, p. 21). ¿Qué supone entonces un proceso de subjetivación política? Lo político, para el autor, implica el encuentro de "dos procesos heterogéneos": el del gobierno, que "consiste en organizar la reunión de los hombres (sic) en comunidad y su consentimiento, y descansa en la distribución jerárquica de lugares y funciones", al que

3 Además de esta línea temática, en la que se inscriben trabajos como los de Mezzadra (2005), Suárez Navaz et al. (2007), y Varela Huerta, (2013; 2015), la autora distingue otras dos: la dedicada al voto migrante, tanto respecto del país de origen como del de destino -por ejemplo, Franzoni \& Rosas, (2006); Finn (2020)-, y la que se ocupa de las prácticas de organización de y para migrantes -por ejemplo, Luque, (2007); Jensen \& Perret, (2013)-. También es posible encontrar textos comparativos, como el de Domenech \& Boito (2019), que exploran las singularidades de experiencias de luchas migrantes en el cono sur respecto de otras desarrolladas en Europa y América del Norte, o que abordan las posibilidades de articulación de estas luchas con otras, y su relación con diferentes clivajes e intersecciones (Caggiano, 2006; 2014: Garrido Muñoz de Arenillas \& Cubero Pajares, 2019).

4 En Santiago residían en 2017112.439 migrantes internacionales, 28\% de su población total (http://resultados. censo2017.cl/Region?R=R13), y en Antofagasta 37.757 personas, 11\% de la población comunal (http://resultados. censo2017.cl/Region?R=R02). 
denomina "policía", y el de la igualdad, que concibe como "el juego de prácticas guiadas por la presuposición de la igualdad de cualquiera con cualquiera y de la preocupación por verificarla" (Rancière, 2006, p. 17), a lo que llama la "política". A partir de estas nociones, la subjetivación política es entendida como "el acto de la igualdad -o el tratamiento de un daño- de gentes que están juntas, por mucho que estén entre" (Rancière, 2006, p. 22). El autor ejemplifica esta noción al hilo de la subjetivación política en tanto proletarios, entendida como

"nombre 'propio' de gentes que estaban juntas, por mucho que estaban entre: entre varios nombres, status o identidades; entre la humanidad y la inhumanidad, la ciudadanía y su negación; entre el estatus del hombre (sic) de la herramienta y el del ser hablante y pensante" (Rancière, 2006, p. 21-22).

Como veremos a partir del análisis de las experiencias que describe el artículo, en algunos de los casos es posible encontrar una condensación incipiente de un-sí-con-otros en torno a un sujeto construido en formas de lucha que se articulan a partir de la desigualdad de clase en la formación social del capitalismo neoliberal, y la desigualdad que instituye el Estado-nación entre ciudadano y no ciudadano.

En estrecha relación con esta idea de subjetivación política para pensar esa dimensión de las experiencias migratorias, dentro de esta caja de herramientas teóricas de interpretación recurrimos también a la noción de luchas migrantes, surgida desde la perspectiva de la autonomía de las migraciones (Mezzadra, 2012; De Genova et al., 2015; Mezzadra \& Neilson, 2016). Si bien el concepto tiende a vincularse con las resistencias de las personas migrantes a las diversas restricciones impuestas por las diferentes expresiones de los regímenes de control de la movilidad, o a luchas por la libertad de movimiento (Varela Huerta, 2015), la idea de luchas migrantes, según De Genova et al. (2015), alude a una variedad de experiencias migrantes que abarcan, pero no se reducen, a ese aspecto, y que pueden "encapsularse" en dos significados:

"En primer lugar, ...indica luchas más o menos organizadas en las que los migrantes desafían, derrotan, escapan o alteran abiertamente la política dominante de movilidad (incluido el control de fronteras, la detención y la deportación), el régimen laboral o el espacio de la ciudadanía... En segundo lugar, ....se refieren a las estrategias diarias, los rechazos y las resistencias a través de las cuales los migrantes representan su presencia (impugnada), incluso si no se expresan o manifiestan como batallas 'políticas' que exigen algo en particular" (De Genova et al., 2015, p. 27, traducción propia).

Es en ese sentido amplio que esta noción operará en el análisis que se propone en el artículo, considerando además un alcance que realiza Perissinotti (2016), que hablando de "luchas de la migración" más que de luchas migrantes, busca englobar con la expresión aquellas que: 
"aún si no se sostienen en la identidad migratoria de quienes las llevan adelante, sí expresan las múltiples desigualdades que atraviesan y configuran a los migrantes que transitan los espacios urbanos contemporáneos. Esto implica reconocer que la experiencia de la migración define las formas, temporalidades y acciones que adquiere la lucha, incluso si esta no se encuentra vinculada a la condición jurídica de la migración" (Perissinotti, 2016, p. 72).

Esta precisión que realiza la autora, ocupándose de luchas por la ciudad protagonizadas por migrantes, sobre todo mujeres, en la ciudad argentina de Córdoba, nos permite entender las especificidades que le imprime la situación migratoria de sus protagonistas a las experiencias que describiremos, aunque no se trate necesariamente de luchas por el acceso a la regularidad migratoria.

\section{Los aspectos metodológicos}

De un corpus textual más amplio, que aún está en construcción ${ }^{5}$, se consideraron para el análisis que se presenta en este texto los relatos de vida de 9 mujeres (cis y transgénero) migrantes organizadas 6 de Santiago y Antofagasta, y entrevistas a 4 informantes clave nacionales (3 mujeres cis y transgénero y un varón), además de acompañamientos de observación en algunas actividades de las organizaciones. Las migrantes entrevistadas provienen de Bolivia, Colombia, Ecuador, Perú y República Dominicana, tenían entre 24 y 52 años al realizar los encuentros, y su tiempo de permanencia en Chile iba de los 2 a los 24 años. Dos de ellas estaban desocupadas, y el resto se dedicaba al aseo en casas particulares o empresas, el cuidado de niños y el trabajo sexual.

La selección de estos/as actores y actrices se relaciona con su vinculación reticular a cuatro experiencias de organización social, de diferente carácter-tanto respecto del motivo que generó la organización como de sus dinámicas de funcionamiento-, que desarrollaron alguna forma de respuesta de solidaridad y apoyo frente al "estallido social" o la situación generada por la pandemia, o ambas contingencias. El hecho de que los relatos de vida migrantes seleccionados pertenezcan a mujeres se relaciona con su participación mayoritaria en la organización de estas instancias de apoyo.

Un criterio de selección de las personas migrantes que han formado parte del estudio fue que estuvieran atravesando una situación de precariedad al momento de construirse los relatos de vida, traducida operacionalmente en estar desocupada o poseer un trabajo precario, y/o residir en condiciones de habitabilidad precarias ${ }^{7}$. En términos generales, entendemos estas situaciones de precariedad como "un proceso social particular compuesto de un conjunto de factores estructurales", y de los discursos y prácticas desplegados por

5 Hasta el momento se han realizado 40 relatos de vida con personas migrantes organizadas y no organizadas de Santiago y Antofagasta; entrevistas a informantes clave y expertos, y acompañamientos de observación a actividades de las organizaciones y trámites.

6 Que pertenecen a alguna organización social, ya sea como dirigentes o participantes.

7 Con la idea de habitabilidad precaria me refiero tanto a la materialidad de la vivienda (que no es apropiada ni en términos de uso ni de seguridad estructural) como al entorno en que esta se ubica (malas condiciones de salubridad, de conectividad y de urbanización). 
personas o por "un grupo social que soporta la institucionalización de un sistema de desigualdades sociales derivadas de la adopción de un determinado [modelo] de desarrollo". Esos discursos y prácticas están orientados a "obtener los recursos para satisfacer las necesidades consideradas socialmente como básicas y adecuadas a la preservación de la dignidad humana" (Argüello, s. f., p. 4).

\section{Entre el estallido y la pandemia: un contexto excepcional para una precariedad estructural}

El llamado "estallido social" chileno, que se inició el 18 de octubre de 2019 y se ha extendido eventualmente hasta el comienzo de la pandemia de coronavirus, en marzo de 2020, alude a una masiva y multiforme emergencia de protestas sociales en la que confluyeron y se ensamblaron diversas banderas de lucha-educación gratuita y de calidad, salud para todos, no más AFP (aseguradoras de fondos de pensiones), reclamos medioambientales y contra el extractivismo en sus diversas formas, igualdad de género, reconocimiento y autonomía para los pueblos indígenas, entre otras-, todas las cuales tienen como horizonte común la desigualdad como principal materialización del régimen económico, sociocultural y político neoliberal imperante en Chile desde la dictadura cívico-militar del general Pinochet.

Estos acontecimientos, detonados por una evasión masiva del pago del tren subterráneo de parte de estudiantes secundarios/as, tras un alza del pasaje, y respondida con una violenta represión estatal, tuvieron su expresión en marchas multitudinarias a lo largo del territorio nacional, cacerolazos masivos, performances, asambleas y cabildos, además de saqueos, destrozos y enfrentamientos entre carabineros y la llamada "primera línea", grupos de jóvenes que hicieron frente a la represión estatal sistemáticamente.

Frente a estos sucesos se hicieron visibles, y también se multiplicaron, estrategias de solidaridad y resistencia colectiva como las ollas comunes, las que después siguieron funcionando ante la situación de empobrecimiento causada por la pandemia ocasionada por el virus Covid-19, que continúa afectando a la población del país hasta el momento, y que ha tenido mayor incidencia aún en la población migrante. La encuesta CASEN 2020 mostró que, mientras en la población nacional la pobreza llegó al 10,8\%, y la pobreza extrema al 4,3\%, entre las personas migrantes esos valores alcanzaron el $17 \%$ y el $7,9 \%$, respectivamente. En los territorios que fueron escenario del estudio, estos indicadores agregados se materializaron en pérdida de empleos y mayor precarización de los existentes, además de nuevas situaciones de allegamiento o deterioro de las condiciones de vivienda, por la imposibilidad de seguir pagando los arriendos.

A su vez, en el marco de una "política migratoria de hostilidad" (Domenech, 2020) que excede el escenario nacional, pero que ha adquirido en Chile especial virulencia -expresándose en un incremento de expulsiones espectacularizadas (Thayer, 2020) y otras medidas restrictivas orientadas especialmente a ciertos grupos nacionales (Stang et al., 2020)-, se produjo además un cierre de las fronteras como medida ante la pan- 
demia, que se ha extendido por varios meses (con aperturas parciales). Esa situación dejó a la deriva a muchos/as migrantes que estaban ya en condiciones de precariedad, y que durante los primeros meses de pandemia acamparon frente a los consulados de sus países de origen, a la espera de la facilitación de medios para el retorno, o alojados en campamentos en el norte, Antofagasta por ejemplo, dependiendo en gran medida de la sociedad civil organizada, nacional y migrante, que se había reactivado y fortalecido con el "estallido social". Este es el escenario en el que se producen las experiencias de solidaridad organizada que buscamos analizar, al hilo del propósito de este artículo.

\section{Experiencias reticulares de solidaridad}

Una de estas experiencias comienza a gestarse en 2015, cuando a partir de una iniciativa de trabajadoras sexuales migrantes que desarrollan su labor en un barrio de Santiago se constituye una Fundación que las agrupa. El contexto es más amplio: el espacio de encuentro comunitario en torno a la activa junta de vecinos del sector, que se ha preocupado de incorporar a la más amplia representación posible de actores y actrices sociales del territorio. En la gestación de la Fundación de trabajadoras sexuales migrantes desempeñó un rol muy activo Eugenia ${ }^{8}$, una trabajadora sexual chilena, miembro de la comisión de la junta de vecinos:

"todas migrantes, soy yo la única infiltrada en esto, porque como somos compañeras y como ellas saben que yo he participado en distintas organizaciones y sé un poquito más en algunas cosas, me iban preguntando constantemente, entonces yo le dije: 'chiquillas, yo les puedo ayudar como secretaria'. Yo no estoy en la directiva, en los papeles, nada, yo las ayudo por el cariño que les tengo, por un compromiso moral, por compañerismo en ser trans y trabajadora sexual" (Eugenia, noviembre 2019).

La agrupación tiene un horizonte más bien funcional, como observan tanto Eugenia como Greta, migrante trans ecuatoriana (33 años, 5 en Santiago) y miembro de la Fundación:

"yo llego [a la Fundación] porque todas las trabajadoras sexuales, las que trabajábamos en la calle, teníamos que ir a la Fundación porque, bueno, ahí hacíamos las reuniones, hablaban de los problemas que habían en la calle con personas compañeras, había la problemática del quitar dinero, de las personas que te explotaban, cosas como esas. (...) Nunca pensé que iba a pasar esto de la pandemia, más yo lo hacía era por el tema de los preservativos, porque igual comprar ahora una caja de preser-

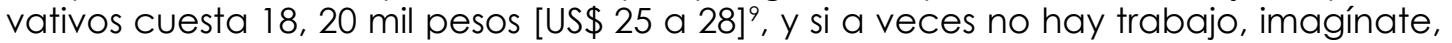
no hay para comprar preservativos... Entonces... opté por entrar en eso y yo le dije...: 'Bueno Eugenia, vamos arando, y por medio de que ustedes me ayuden, yo lo hago'. Obviamente también tengo contacto con... la asistente social del... [hospital de urgencias] y siempre ella me ha dicho que cuando ella pueda ayudarme con el tema salud o el tema de cualquier compañera, igual tengo a la presidenta de Amanda Jofré [Corporación Chilena de Personas Trans]. Entonces, igual también trabajamos con las inmigrantes para lo que es el test PCR y esas cosas" (Greta, agosto 2020).

8 Los nombres de las y los entrevistadas/os, los de lugares acotados, y de organizaciones sociales, son ficticios, para resguardar el anonimato de los participantes en el estudio.

9 Según la cotización del Banco Central de Chile al 1/6/2021. 
El extenso fragmento del relato de Greta es representativo del modo en que se van construyendo estas experiencias reticulares de apoyo y solidaridad más o menos organizadas, que se van entramando a partir de propósitos bien concretos y pragmáticos-como obtener las cajas de preservativos para el trabajo-, y de la búsqueda de soportes emocionales, como la red de conocidas y amigas que se va armando en el camino. La experiencia organizacional va articulando a migrantes con actores y actrices nacionales, tanto individuales (la trabajadora social del hospital) como colectivos (Eugenia como miembro de la junta de vecinos, la organización Amanda Jofré), en un ensamblaje de protección que provee información y diversos tipos de recursos (materiales y simbólicos) que permiten sortear las restricciones cotidianas.

Esa retícula de apoyo puede transformarse en una malla de contención ante situaciones críticas, como la que ha supuesto la pandemia de coronavirus. El trabajo sexual, una actividad que generalmente se desarrolla en las noches, se vio muy afectado por el toque de queda que se impuso desde el 22 de marzo de 2021 hasta la actualidad como medida de restricción del movimiento a causa de la pandemia, a la que se sumaron además, al principio, largas cuarentenas, que se han flexibilizado pero no desaparecido, y que junto con otras medidas sanitarias -como el distanciamiento social- lo han perjudicado. Greta da cuenta en su relato de esta afectación, con incidencia directa en los ingresos. La olla común organizada por la junta de vecinos del barrio desde el comienzo del estallido y hasta la actualidad operó como un soporte para algunas de ellas; la Fundación, en tanto respaldo organizacional, también permitió demandar colectivamente al Estado la caja de alimentos que no les había llegado:

"el apoyo de la municipalidad que recibí fue por medio de la Fundación de nosotras. (...) la única caja que recibí, como te dije, que me dio la municipalidad, pero porque nosotros como organización, con Eugenia, nosotros mandamos una carta a la municipalidad pidiendo ayuda, entonces ahí fue que nos dieron 20 cajas primero y después sí nos repartieron, pero sólo una pura vez" (Greta, agosto 2020).

Otra de las experiencias que nos interesa analizar se desarrolla en Antofagasta, y emerge a causa de la situación de pandemia, aunque se alimenta de una red de apoyo construida previamente a partir del trabajo de una Fundación nacional que lleva más de dos décadas dedicada a los derechos de las mujeres, especialmente trabajadoras sexuales, pero sobre todo, gracias al rol de Susana. Ella es una ex trabajadora nocturna chilena que se transformó en dirigente social a partir del vínculo con esta organización, que la apoyó para "sobrevivir" una situación de violencia de género, y que a partir de eso ha desplegado una labor territorial histórica en esa comuna del norte. En esa actividad, se ha relacionado en los últimos años con muchas trabajadoras migrantes, cuyo número ha crecido en esta ocupación (Pavez, 2016), de la mano del incremento de la población migrante en la ciudad. Susana trabaja principalmente en la prevención y el cuidado de la salud sexual de las trabajadoras, y en la orientación y el apoyo ante el abuso laboral. 
El estallido primero, y la pandemia después, dejaron a muchas de estas migrantes sin poder trabajar. Mercedes (dominicana, 30 años, 3 viviendo en Antofagasta), trabadora nocturna y miembro de la red que armó Susana, da cuenta de esto:

"lo que sí estaba complicado aquí era lo de la protesta, eso sí estaba bien feo... no podíamos trabajar. Abrían y había que cerrar por la multitud, por el desorden, esas cosas, complicó mucho el trabajo, ahí fue cuando comenzó a complicarse (...) Trabajé en locales un buen tiempo hasta que pasó lo de la pandemia y los cerraron.... más nunca han vuelto a reabrir ni nada de eso" (Mercedes, marzo 2021).

Ante la situación de empobrecimiento que estaban viviendo por el desempleo, Susana comenzó a articular a diversos/as actores y actrices con los que se ha ido vinculando a partir de su trabajo territorial de años: organizaciones sociales (incluida aquella para la que trabaja), amigos y amigas feriantes y rotarios/as, ex autoridades de gobierno, funcionarios/ as del Estado sensibles con la situación de las personas migrantes, entre otros, y a partir de la postulación a proyectos y donaciones implementó dos instancias de asistencia: una olla común, que luego derivó en "olla seca" (bolsa con comestibles), y un grupo de madrinas para el apoyo a algunas de estas mujeres que quedaron embarazadas durante la pandemia:

"empezaron a aparecer mujeres embarazadas en tiempo de pandemia, y ahí armamos el grupo..., empezamos con 7, 8 mujeres embarazadas, y el grupo en general ahora, entre embarazadas y las que ya tuvieron su bebe, son 26 mujeres" (Susana, abril 2021).

Mercedes y Pamela (colombiana, 24 años, 2 en Antofagasta) son dos de las mujeres de este grupo:

"como no tengo documentos no es fácil adquirir ese tipo de ayudas [entregadas por el gobierno por la situación de pandemia], la única ayuda que recibí fue por Susana..., del resto, del gobierno, pues no, porque no tengo documentos" (Pamela, marzo 2021).

Estas dos redes son expresiones de lo que hemos llamado experiencias reticulares de solidaridad, caracterizadas por esta articulación de actores y actrices provenientes de ámbitos diversos, tanto nacionales como migrantes, que se van entramando en red en torno a propósitos de acompañamiento y apoyo, y que van proveyendo, según sus posibilidades, diferentes recursos materiales y simbólicos para sortear situaciones de precariedad, contingentes o (y) estructurales. Aunque la vinculación de los actores y actrices migrantes que las componen tiene más que nada un horizonte funcional, y no podrían considerarse instancias de subjetivación política en los términos en los que la hemos definido en este artículo, estas experiencias pueden pensarse como instancias de producción de subjetivaciones resistentes.

Esta afirmación debe considerarse en sus debidas dimensiones; no pretendemos hacer apología de una suerte de estoicismo comunitario frente a la pobreza, la ausencia del Estado o el "salvajismo" del mercado. Aun así, estas redes solidarias pueden ser pensadas como prácticas micropolíticas de la vida cotidiana, desplegadas en los intersticios y los márgenes de las instituciones, "en los resquicios y grietas de los aparatos de saber-poder" 
(Perrig y Gudiño, 2008, p. 43), que les permiten "resistir y negociar los modos en los cuales las fronteras marcan y constriñen sus vidas", como sostienen Mezzadra y Neilson (2016, p. 398) hablando de "luchas de fronteras".

Estas prácticas cotidianas habilitan procesos de subjetivación en cierto modo disruptivos y resistentes a las lógicas del capitalismo neoliberal, cuyo sujeto hegemónico es el homo œconomicus (Foucault, 2008), esto es, el sujeto del intercambio, de la empresa y la producción -no de la solidaridad-, más próximo a las estrategias individuales y competitivas que las colectivas y de apoyo mutuo.

Como sostienen Mezzadra y Neilson (2016),

"[l]a lucha, en este sentido, se refiere no sólo a los movimientos y a las acciones políticas organizadas, sino también a las prácticas y comportamientos sociales que pueden ser precondiciones fundamentales para estos movimientos y estas acciones, pero que son frecuentemente asignadas a la esfera de lo pre-político" (Mezzadra y Neilson, 2016, p. 398, énfasis propio).

En efecto, el estudio ha permitido encontrar instancias en que esas precondiciones derivan en acciones políticas organizadas y generan, en consecuencia, procesos de subjetivación política de estas/os migrantes, como analizamos en el próximo apartado.

\section{Experiencias de politización en la precariedad}

Las subjetivaciones resistentes construidas en esas experiencias reticulares de solidaridad son, entonces, pre-condiciones para estos caminos de politización, aunque esto no significa, por supuesto, que este curso que estamos describiendo sea indefectible. En ese sentido, Nidia (peruana, 28 años, 10 en Santiago) podría considerarse un "caso bisagra", es decir, una experiencia de tránsito entre estas subjetivaciones, cuya deriva, de todos modos, no es posible prever. Ella es miembro de un comité de vivienda que también se formó al alero de la junta de vecinos del barrio de Santiago a la que nos referimos en el apartado previo. La razón por la que se unió a la organización es, como en los casos previos, funcional: la posibilidad de acceder, a mediano plazo, a una vivienda, porque "yo sé que si lo hago sola ningún banco me va a prestar plata [para comprarla], ninguno" (Nidia, agosto 2019).

Nidia participa de las diversas actividades de ese espacio comunitario: es parte de una de las comisiones del comité, asiste a las asambleas, a veces colabora con la olla común que se organizó desde el estallido. También ha participado en marchas y manifestaciones ligadas con la causa que reúne al comité. En principio, esa implicación parecía estar relacionada con una de las reglas que rigen el funcionamiento de la organización: si se falta a tres actividades consecutivas, se pierde la calidad de miembro, la que se otorga a otro/a vecino/a de la lista de espera. Sin embargo, en los acompañamientos a las actividades de la organización, se pudo observar un vínculo que excedía esa obligación con un fin pragmático. 
Nidia me contaba que al principio sentía miedo participando de las manifestaciones, pero poco a poco empezó a sentirse más segura e, incluso, a experimentar una sensación liberadora:

"porque a veces uno no tiene dónde exponer todo lo que tú piensas, puedes conversarlo, pero no gritarlo a la gente, que todos sepan que hay este problema de la vivienda, que el Estado a veces no te apoya, entonces uno libera todo eso gritándolo" (Nidia, octubre 2019).

En los últimos meses de 2019, en pleno "estallido" -en un clima social de cierta efervescencia festiva y esperanzadora para organizaciones como la suya-, la acompañé junto a otros miembros del comité a una funa ${ }^{10}$ de un funcionario municipal que estaba poniendo un obstáculo burocrático a la búsqueda de un terreno, para poder construir su proyecto habitacional. A pesar del temor que eso le causaba, y de la presencia intimidante de numerosos carabineros, tuvo un rol protagónico en esta intervención. Regresamos en el metro conversando, y volvió a hablarme de lo liberadoras que se sentían esas experiencias, y de la emoción que le generaba el logro concreto de ese día: que el funcionario los recibiera.

A diferencia de las experiencias anteriores, estas han supuesto un rol muy significativo de actores y actrices nacionales, tanto individuales como colectivos, con un importante nivel de politización. Es decir, actores que, por diferentes vías, han sido parte de una construcción de un-sí-con-otros a partir de una causa construida en torno a una forma de desigualdad (de daño) que ha permitido la emergencia de un sujeto de enunciación. En el discurso de Nidia se puede encontrar ese proceso de subjetivación política incipiente: ella quiere gritar, dice, para que todos sepan el "problema que hay con la vivienda", y la desatención del Estado a ese problema. El señalamiento del rol significativo de actores y actrices nacionales en estos procesos no implica desconocer la capacidad de agencia de estas mujeres migrantes, que iremos describiendo en este apartado.

En los relatos de vida de Nidia, y de otras dos mujeres migrantes miembros del mismo comité -Ely (colombiana, 35 años, 6 en Santiago), y Estela (peruana, 43 años, 17 en Santiago)-, aparecen dos actores/actrices con un influjo muy importante sobre su participación, y en su mirada más amplia sobre "el daño" que, en el caso de Nidia, deviene una subjetivación política incipiente: por un lado Ingrid, la dirigente chilena que lidera la junta de vecinos y el comité, y por el otro, una organización histórica en la lucha por la vivienda en Chile, que les ha dado "una buena base", según palabras de Nidia:

"han llegado ante las reuniones y nos han contado sobre su experiencia, cómo han luchado, cómo han sufrido... ellos han luchado como 10 años y se han movido, han quemado terrenos, han hecho de todo... se han expuesto, se han quedado detenidos... La señora Ingrid dice igual, 'así tengamos que quedar detenidos, igual vamos', pero claro, si alguien queda detenido también va un grupo a apoyar, no es que 'ya, se fueron detenidos, problema de ellos', no, el comité mismo tiene que ir y apoyar ahí" (Nidia, octubre 2019).

10 Entendida como "acto público de repudio contra el actuar de una persona o grupo que ha cometido un acto que se considera ilegal o injusto" (Schmeisser, 2019, p. 6). 
"la señora Ingrid ha sido muy especial, porque la verdad es que ha sido así, siempre se preocupa de cada uno de nosotros, está pendiente en qué nos puede ayudar, y nos dijo 'chiquillos, en lo que se pueda ayudar uno a los otros, una completada [venta de sándwiches], algo nos inventamos para salir adelante en las circunstancias', ha sido un apoyo muy grande" (Ely, noviembre 2019).

No es un elemento menor, como adelantábamos, el miedo a protestar y manifestarse que expresan casi todas las migrantes consideradas para este análisis, ni la razón principal que anima ese temor, estrechamente relacionada a su carácter de migrantes:

"uno como inmigrante no puede protestar, pero igual uno hace acto de presencia... nosotros vivimos aquí, pero como tal, nos tenemos que acoger a las reglas de aquí, no decir 'no, es que no me gusta', porque igual nosotros no somos chilenos, y hasta donde sé, creo que el que puede protestar es una persona que está nacionalizado, pero hasta donde sé, como inmigrante no. Porque te ponen a firmar, te dan tiempo, o si no, te sacan" (Ely, noviembre 2019).

El miedo a la expulsión es un sentimiento común en el/la inmigrante, que encarna en el cuerpo la expulsabilidad permanente que pesa sobre su presencia. Sayad habla de un sentimiento de deber de cortesía, en tanto huésped, que experimenta el extranjero, y el modo en que incide en su implicación política: "Es inconscientemente la cortesía la que impide al extranjero tomar partido políticamente en los asuntos políticos (interiores y exteriores) del país huésped" (Sayad, 2010, p. 394).

A pesar de estos temores, muchos/as migrantes fueron parte activa de las protestas en el marco del estallido social. Y entre aquellos/as que no se atrevieron a participar de las marchas, ya sea por el temor a la expulsión, o por otro tipo de miedos -varios/as migrantes colombianos/as refirieron recuerdos de la violencia en su país de origen-, pero que formaban parte de organizaciones vinculadas a experiencias reticulares de solidaridad como las descritas previamente, había un sentimiento de simpatía y adhesión por las causas del movimiento, que apareció profusamente en las entrevistas:

"estánensu derecho, igual, osea, acá como quelagenterica se beneficia másylagente pobre no está ni ahí, entones eso sí es lo que está pasando" (Estela, noviembre 2019).

Sin embargo, en aquellas mujeres migrantes que venían experimentando previamente procesos de subjetivación política a partir de la participación protagónica en las causas de sus organizaciones, la implicación en las movilizaciones y protestas fue intensa; se sintieron directamente interpeladas por el movimiento. Julia (peruana, 52 años, 25 en Chile y 10 en Antofagasta), Graciela (colombiana, 35 años, 8 en Antofagasta) y Elena (boliviana, 46 años, 23 en Antofagasta) son ejemplos claros de ello. Las tres son dirigentes de los comités de vivienda de los campamentos ${ }^{11}$ en los que residen en Antofagasta, y forman parte de una organización de pobladoras y pobladores por la vivienda digna, con presencia en varias regiones del país.

11 En Chile, se entiende por campamento a un asentamiento "donde ocho o más familias, que habitan viviendas agrupadas o contiguas, se encuentran en una situación irregular de tenencia del terreno y carecen de acceso regular a uno o más servicios básicos de la vivienda (agua potable, energía eléctrica y alcantarillado/fosa séptica)" (CIS, 2018, p. 3). En 2016, Antofagasta era la región con más migrantes viviendo en campamentos $(32,9 \%)$ (CDH UDP, 2016). 
Julia describe esta implicación "densa" con el movimiento:

\begin{abstract}
"Antofagasta estalló por todos lados, y una de las poblas [poblaciones, o barrios] que estalló...., ha sido muy fuerte ahí, a veces salen a hacer... barricadas, es el sector Blest... a unos 300 metros del campamento... Entonces ellos salieron a darlo todo, los cabros [adolescentes y jóvenes] salieron a darlo todo allá, barricadas, todo, y no tenían cómo resguardarse... hablamos con el caballero del No+AFP...: 'Ya pues, habla con el cura para que abra la iglesia, que esto de aquí, que esto de acá'. Y abrieron la iglesia para hacer un Comité de Resguardo, y los únicos que llegamos con medicamentos y cosas fuimos nosotros desde nuestras casas" (Julia, mayo 2020).
\end{abstract}

A fines de noviembre de 2019, en pleno estallido, acompañé a Julia y Graciela -forman parte del mismo comité- a una actividad que habían organizado con la junta de vecinos del sector Blest. La actividad convocante era un operativo de salud que terminaría con una tallarinada para todos los participantes y, según decía Julia, con "los cabros de la primera línea". Muchos de los miembros de la junta de vecinos de Blest no estaban de acuerdo con invitar a estos jóvenes, así que se generó una situación de tensión que Julia manejó muy bien, en pos de la búsqueda de articulación con estos/as vecinos y vecinas, algo que la preocupa. De todos modos, al final de la actividad tomó la palabra "defendiendo la necesidad de apoyar a los cabros de la primera línea, que no son delincuentes, que son nuestros hijos, y que están peleando por nosotros" (notas de campo, noviembre 2019).

Elena es dirigente del comité de otro campamento de Antofagasta. Nuestro primer encuentro ocurrió mientras organizaba una comida para las y los vecinas/os que estaban ayudando en la reconstrucción de la casa de una compañera tras un incendio. Poco después viajó a Santiago, como parte de una delegación que se presentó ante el Tribunal Internacional de Desalojos ${ }^{12}$-que sesionó en Santiago en diciembre de 2019-, porque su campamento había sufrido un violento intento de desalojo. En ese viaje fue hasta la Plaza Dignidad, el epicentro de las protestas en la capital:

"nosotros como inmigrantes extranjeros no cierto, indígenas, llegamos ahí justamente, me sacaba fotos, me parece que me vieron y me gritaron...: 'Extranjero, únete a la lucha'... iqué te parte el corazón ahí! Y cómo esperar entonces, tenís [tienes] que unirte" (Elena, diciembre 2019).

En el discurso de las tres dirigentes, pero sobre todo en el de Julia y Graciela, se observa la coagulación progresiva de un sí-con-otros en tanto que comunidad de pobladores, un lugar de enunciación en el que la clase atraviesa la posición migrante. Elena, por su parte, articula en su discurso su posición de migrante con la de indígena. Y en las tres, la experiencia subjetiva del género le da forma al sujeto de la enunciación. Esta intersección de dimensiones, que construye esa específica experiencia de desigualdad, también le da una forma particular a la construcción de este sí-con-otros en torno a ese daño.

12 Se trata de un "tribunal popular y de opinión, que fue establecido en 2011 por la Alianza Internacional de Habitantes $(\mathrm{AlH})$ y organizaciones sociales durante las Jornadas Mundiales Cero Desalojos y que tiene por finalidad analizar y cuestionar de manera práctica e interactiva casos de desalojos forzados que tienen lugar en distintas partes del mundo" (en línea, https://esp.tribunal-evictions.org/, consultado el 3/5/2021). 
A través de sus enunciados puede advertirse el diálogo con organizaciones como la que agrupa a estas dirigentes, que han tenido un rol significativo proveyendo a actores y actrices como ellas de "un nuevo lenguaje político" (Angelcos, 2020), un lenguaje que, por supuesto, es reapropiado y resignificado. Julia habla, por ejemplo, de "normalizar la solidaridad", como enunciado que condensa el sentido de las subjetividades resistentes a las que aludíamos antes -la solidaridad como sentido contra-hegemónico en el capitalismo neoliberal-. Lo dice describiendo los múltiples problemas que debieron afrontar como comunidad en pandemia, incluyendo el alojamiento en el campamento de muchos migrantes precarizados, varados por el cierre de las fronteras:

"cuando tú... normalizas la solidaridad, por ejemplo, haces que todo esto vaya pasando en el día a día, aquí, por ejemplo con los peruanos varados en Antofagasta... Con nuestras vecinas que se les queman sus casas mientras estábamos juntando plata para poder enterrar a una viejita de 72 años que murió de un infarto y que sus hijos no se podían acercar a ella, porque esos dos hijos estaban con Covid, los vecinos eran los que estaban levantando los esfuerzos para poder darle una cristiana sepultura... estamos juntando arroz para que otros vecinos coman, estamos sanitizando casas para nuestros vecinos de Covid, y todos los vecinos en disponibilidad abierta y a veces sin contar con recursos" (Julia, mayo 2020).

El relato de Julia es la mejor descripción empírica de los nudos de sentido en torno a los cuales se construyen estas subjetividades resistentes, devenidas políticas. ¿ Cómo ocurren esos procesos? En estos casos, la red va conectando actores y actrices, individuales y colectivos, con discursos más politizados, en el sentido en que Rancière (2006) define lo político, lo que ocurre, además, en el marco de causas también más politizadas, como la de la vivienda (Angelcos, 2012). Lógicamente, en los actores y actrices migrantes que forman parte de estas experiencias también hay características y situaciones específicas que propician la articulación con esos discursos y prácticas -un aspecto que excede el propósito de este artículo-.

En esta conexión reticular aparecen actores y actrices que realizan un trabajo territorial muy significativo para estas mujeres migrantes en el campamento; es a partir de esa labor, y de su enfoque, que se van urdiendo estos lazos decisivos para el proceso de subjetivación política de Julia y Graciela. Ambas identifican claramente a este actor colectivo, una ONG, y dentro de ella, a un dirigente social importante. Ambas llegan al contacto con estos actores buscando ayuda ante situaciones de violencia de género.

"yo soy todo lo que soy porque Prisma [la ONG] hizo que yo hiciera lo que yo hago, o sea, me hizo, me conectó con la gente, me ayudó a empoderarme, me ayudó a salir de mi problema de que tenía, de violencia intrafamiliar, y me logró empoderar, porque son un grupo de psicólogos, periodistas y todo, y ya el resto bueno, ahora nosotros caminamos solos, pero en los primeros años ellos estuvieron ahí con nosotros" (Julia, noviembre 2019).

Es Graciela quien conecta a Julia con Prisma; la forma en que ella se vinculó inicialmente con la ONG ilustra estos recorridos que entraman recursos, materiales y simbólicos, frente a situaciones de precariedad y violencia. Primero se relacionó con el Plan de Superación de 
Campamentos que implementó el gobierno regional de Antofagasta ${ }^{13}$, a partir de allí supo de la existencia del Centro de la Mujer, y comenzó a asistir, porque estaba viviendo una situación de violencia intrafamiliar. Esta coincidencia en la alusión a la violencia de género en estas trayectorias de mujeres dirigentes no es casual, y aunque su abordaje excede los objetivos y el espacio de este artículo ${ }^{14}$, ilustra con claridad la necesidad de una mirada interseccional para el análisis de estos procesos en los que es ese cruce de dimensiones (de género, clase, etnia, "raza", extranjeridad) el que permite entender tanto la forma que adquiere en estos casos la desigualdad como las luchas que ese menoscabo anima.

Graciela tomó también un curso de "lideresas" que dictó en el campamento una universidad, lo que la acercó al feminismo. En paralelo conoció el accionar de Prisma, dado que ella ya estaba desarrollando un trabajo de dirigencia social en su campamento, y accedió de esa forma a varias instancias en las que fue nutriendo su discurso de dirigente:

"Técnicamente [Prisma nos ha ayudado], nos han enseñado a ser organizados... trayéndonos cursos, capacitaciones para aprender entre nosotros a desarrollarnos, también con la comunidad, así como lo hicieron con promotores interculturales" (Graciela, noviembre 2019).

En el caso de Julia, Prisma la contrató para ser "monitora de participación ciudadana" cuando se quedó sin trabajo, la conectó con una red nacional de organizaciones de migrantes, con la organización nacional de pobladores por la vivienda, las apoyó para postular a un proyecto internacional para realizar un estudio de suelo y mapeos que les permita luchar por la radicación de su campamento en el lugar en que está: "todas mis afiliaciones tienen un nombre, se llaman Cristian González", dice Julia. Ella misma relata cómo va nutriendo su trabajo de los recursos que esta red que crece le va proveyendo:

"Entonces de qué nos sirvió hacer, por ejemplo, [esta organización nacional de pobladores por la vivienda] acá en Antofagasta, que se generó un espacio como movimiento. Entonces yo ahora estoy hablando 'esto no es de los campamentos, es de los sin casa, vivienda digna para todos'. Entonces, estamos en eso, y la red nacional [de organizaciones migrantes] es... como el corazón de nuestra vida para nosotros, porque es la que nos instruye, la que nos forma" (Julia, noviembre 2019).

Cristian González, el dirigente de Prisma aludido por Julia y Graciela, coincide en muchos aspectos en la descripción de este proceso, desde su perspectiva:

13 Implementado desde 2015 hasta 2017; para más detalles, véase Stefoni \& Stang (2017).

14 Este es un aspecto muy importante para entender los procesos de subjetivación política de estas mujeres, que se abordará en otro artículo en elaboración. 
"en el campamento ha ocurrido un proceso de politización no explícitamente ideológica... no hemos promovido ni el comunismo, ni el socialismo, ni el anarquismo, pero sí ha sido un proceso de politización en la medida que es un proceso de diálogo entre nosotros y las vecinas y los vecinos, donde hemos ido compartiendo nuestras experiencias y nuestros saberes en torno a cómo el Estado usa de las personas para sus fines y no para los intereses del pueblo (...) Entonces, es una politización no con una sofisticación ideológica, pero sí digamos desde una perspectiva, si uno lo piensa como de educación popular, pega muy bien con las experiencias cotidianas digamos, las trayectorias de las personas" (Cristian, diciembre 2019).

Cristian pone el acento en estas coincidencias entre las trayectorias personales de estas mujeres migrantes con las herramientas argumentativas que estas experiencias de participación les proveen; en el sentido que cobran estas ideas "desde la experiencia de vivirse como una clase subalternizada". Angelcos, explicando un aspecto de la forma en que opera la subjetivación política, echa luz sobre esto que sostiene Cristian: "La subjetivación política implica así una articulación, en permanente tensión, entre la identidad y biografía individual con la construcción de una comunidad de pertenencia" (Angelcos, 2012, s/n). En este caso, el daño que articula esta lucha (la falta de una vivienda digna, y de condiciones dignas de vida) es un elemento clave en la construcción de esta comunidad de pertenencia, este ser-sí-mismo-con-otros. Y el vínculo con estas organizaciones le provee a Julia herramientas para entender las causas de esa desigualdad que la une a los otros, e instalarlas en forma de litigio:

"yo no distingo el poder, lo que yo distingo es la lucha, entonces la lucha, la igualdad de clase, la misma calidad de condiciones, ¿̇me entiende? ...Y la gente, tú te has dado cuenta, es solidaria a morir en todo este proceso ¿̇cachai? [entiendes], y estamos despertando día a día" (Julia, noviembre 2019).

El proceso de subjetivación política de Elena tiene algunos actores en común: Cristian González, quien la contacta con una organización para migrantes que le brinda apoyo jurídico para detener el proceso de erradicación del campamento en que ella es dirigente; y también la organización nacional de pobladores por la vivienda. Pero su politización se inicia de un modo diferente, con una indignación con el dirigente chileno que lideraba el campamento cuando ella llegó:

"el chileno nos manipulaba, entonces como emigrante nosotros quedábamos un poco discriminados, entonces yo decía 'no puede ser esto', porque aquí nos dicen 'ustedes como extranjeros tienen que estar calladitos', porque más bien les están dando un terreno donde vivir, ustedes no pueden reclamar, no pueden afrontar al gobierno, no pueden decir nada, porque como son extranjeros los van a sacar cagando de acá', así nos decían" (Elena, noviembre 2019).

Después, Elena se integra a una escuela para adultos en el campamento, porque dado que empezó a trabajar desde muy niña para ayudar a su mamá con la crianza y el sustento para ellas y sus dos hermanos, en la ruralidad boliviana, no había podido alfabetizarse: 
"la profesora me dice 'tú estás muy empeñada en aprender', 'sí, quiero aprender a leer, escribir, quiero aprender cómo se escriben bien las letras', entonces ella me decía 'pero ¿̇cuál es tu objetivo?', 'quiero ser dirigente, quiero hacer algo para el campamento' (...) quiero saber si de verdad tenemos derecho a una vivienda o no derecho a una vivienda, y cuáles son nuestros derechos como inmigrantes, eso es lo que quería saber" (Elena, noviembre 2019).

Así, Elena empezó siendo delegada de la junta de vecinos, yendo a reuniones en la municipalidad y la intendencia, después se hizo parte de una mesa social regional, conoció a Julia, dice que aprendió mucho de ella, se sumó a la organización de pobladores y pobladoras por la vivienda, y a la red nacional de organizaciones migrantes de la que también hablan Julia y Graciela.

La forma en que Elena construye las razones del inicio de su dirigencia social permiten re-enfocar el análisis hacia la especificidad de estos procesos de politización, que en muchos aspectos se parecen al de los y las pobladores/ras chilenos/as en lucha por la vivienda, tal como los ha descrito Angelcos (2012) a partir de sus estudios. En estos casos se trata de no-nacionales $y$, en términos convencionales, de no-ciudadanos, o sea, de personas que, en teoría, no son "naturales" de este Estado. Por lo tanto, la desigualdad en torno a la cual se establece la lucha tiene cara de Jano: en tanto que pobladores/ras sin vivienda digna -aquí prima un sujeto de clase-, y en tanto que migrantes-no ciudadanos/as -y allí prima el sujeto de la extranjeridad-. Se trata, podríamos decir, de luchas de migración a partir de procesos de subjetivación política en contextos de precariedad. Es por esa razón que sostenemos que en estas experiencias de subjetivación política se pueden encontrar gérmenes de una potencial transformación de la ciudadanía, del modo en que la entendemos y las prácticas con que la materializamos.

Martínez Bonora (2012), siguiendo a Rancière, plantea que

"el obstáculo para una ciudadanía desnacionalizada no solo reside en las características obvias del conflicto 'nosotros nativos' y 'otros extranjeros'..., sino en la dificultad en lograr que el proceso de demanda, de movilización y de argumentación devenga político, en su sentido de litigio, de disputa, de denuncia, de impugnación de la lógica 'natural' de la dominación; impugnación desde la puesta en verificación del principio de igualdad" (Martínez Bonora, 2012, p. 18).

En los procesos de politización de estas mujeres migrantes descritos a lo largo del artículo, el litigio, el punto nodal en torno al que se instituye la lucha por la desigualdad es, podríamos decir, un daño de clase, pero de todos modos tiene la marca de la migración, por ejemplo, en el temor a manifestarse asociado a esa presencia que no deja de vivirse como "prestada". El daño de la extranjeridad no adquiere la misma solidez en su coagulación en estas subjetivaciones políticas, pero aparece de manera significativa y persistente en sus relatos:

"si tú me preguntas si quiero nacionalizarme para ser este... presidenta, diputada, no lo voy a hacer nunca, no me voy a nacionalizar, me tienen que aceptar como soy, peruana residente chilena, con los mismos derechos e igualdad de condiciones" (Julia, noviembre 2019). 
Por eso es que requieren toda nuestra atención, para observar si, y cómo, pueden estar incidiendo en una metamorfosis, desde abajo, de la ciudadanía en un marco más amplio de transformaciones que encontraron en el estallido social una visibilidad ineludible.

\section{Una mirada prospectiva en tiempos constituyentes}

A lo largo de este texto hemos procurado mostrar la articulación de actores nacionales y migrantes en torno a experiencias reticulares de solidaridad que brindaron apoyos de diverso tipo frente a dos acontecimientos específicos: el estallido social y la pandemia de Covid-19, en dos comunas de Chile. Mostramos también la forma en que esas experiencias habilitan la emergencia de subjetivaciones resistentes que, en determinadas circunstancias y condiciones, devienen en procesos de subjetivación política, en el marco de luchas de migraciones. Esas subjetivaciones políticas construyen un sujeto que se enuncia a partir de la desigualdad de clase en la formación social del capitalismo neoliberal, y la desigualdad que instituye el Estado-nación entre ciudadano y no ciudadano. Propusimos también, como una idea que queda abierta a exploraciones futuras, que esos procesos de subjetivación política estarían contribuyendo -junto a otros, como los producidos en el marco de las luchas feministas- a una transformación desde abajo de lo que entendemos y actuamos por ciudadanía.

Pensar estas experiencias desde la idea de luchas de migraciones nos permite poner de relieve la importancia que tienen, para la transformación de los marcos convencionales de la ciudadanía, las prácticas y las reivindicaciones de aquellos/as que no necesariamente son ciudadanos/as en términos jurídicos. Esos marcos convencionales de definición de la ciudadanía consideran centralmente dos elementos: la adscripción de derechos y deberes, y la pertenencia a una comunidad política (Velasco, 2016; Durán Migliardi \& Thayer Correa, 2020). En los Estados modernos, el vínculo entre ambos se ha dado usualmente por la vía de la nacionalidad: los Estados conceden los derechos de ciudadanía a los y las nacionales (por nacimiento o naturalización), y se los niegan a los y las no-nacionales (Velasco, 2016). Al demandar derechos como no nacionales, e implícitamente reclamar la participación en la comunidad política, estas luchas están corriendo los límites de este marco. Los y las migrantes, de este modo, son actores de prácticas materiales con una temporalidad extensa (Mezzadra \& Neilson, 2016), que van creando las condiciones para una transformación de la ciudadanía, y también de la política.

Tematizar la dimensión política de la migración y de las y los migrantes no es un ejercicio teórico inocuo, porque las implicancias de pensar al y la migrante como sujeto político son poderosas, en tanto permiten cuestionar ese vínculo naturalizado entre política y ciudadanía, y entre ciudadanía y Estado-nación. De este modo, como dice Mezzadra, "surge un espacio con una perspectiva diferente y más prometedora, que ofrece la posibilidad de construir coaliciones heterogéneas y bases comunes para que se produzca un encuentro entre los migrantes y otros sujetos en conflicto" (Mezzadra, 2012, p. 177), se abre "todo un 
campo para pensar las resistencias al capitalismo tardío" (Varela Huerta, 2013, p. 218), para articular un sí-mismo-con-otros mucho más amplio, como el que se articuló de manera contingente en el estallido social chileno, que abrió paso al proceso de cambio de una Constitución heredada de una sangrienta dictadura que había sido protegida por décadas por aquello que, en términos de Rancière, podríamos llamar la policía.

En pleno estallido, a fines de 2019, conversando con Graciela, me contaba que el día anterior había participado de un cabildo que se llamó "La constituyente la hace el pueblo", "porque es importante que nosotros como extranjeros empecemos a articular con agrupaciones que están organizando esto", me decía, "lo importante es que den su punto de vista para que nadie quede por fuera, por eso es que yo hablo mucho de una nación pluricultural". Si no entendemos la ciudadanía "como un estatus, sino como una práctica colectiva en permanente reconfiguración" (Gil Araujo y Rosas, 2019), parece obvio que estas subjetivaciones políticas migrantes como las que materializan las palabras de Graciela no pueden sino incidir de manera decisiva en esa reconfiguración.

\section{Agradecimiento}

Este artículo expone algunos resultados del proyecto Fondecy† N 3190674 " Migración, precariedad y ciudadanía: de las tácticas de subsistencia a las estrategias de lucha", financiado por la Agencia Nacional de Investigación y Desarrollo (ANID), Chile.

\section{Bibliografía}

Angelcos, N. (2012). Lucha por la vivienda y politización de las trayectorias individuales. Polis, Revista Latinoamericana, 11 (31), 17-38. doi: http://dx.doi. org/10.4067/S0718-65682012000100002

.(2020). De la vivienda digna a la lucha por la dignidad. Movilización y politización de los pobladores en el siglo XXI. CiperAcadémico. https://www.ciperchile. cl/2020/07/22/de-la-vivienda-digna-a-la-lucha-por-la-dignidad-movilizacion-ypolitizacion-de-los-pobladores-en-el-siglo-xxi/

Argüello, O. (s. f.). Delimitación del concepto "estrategias de supervivencia» y sus vínculos con la investigación socio-demográfica. Programa de Investigaciones Sociales sobre Población en América Latina (PISPAL).

Caggiano, S. (2006). Fronteras de la ciudadanía. Inmigración y conflictos por derechos en Jujuy. En A. Grimson \& E. Jelin, Migraciones regionales hacia la Argentina. Diferencia, desigualdad y derechos. Buenos Aires, Argentina: Prometeo.

- (2014). Desigualdades entrelazadas, luchas divergentes: Migración e industria textil en Argentina. Revista CIDOB d'Afers Internacionals, 107-107, 151-170.

CDH UDP. (2016). Derecho a una vivienda adecuada en Chile: Una mirada desde los campamentos. En Informe anval sobre derechos humanos en Chile 2016 (pp. 81121). Santiago, Chile: Universidad Diego Portales.

CIS (Centro Investigación Social Techo). (2018). Actualización del catastro nacional de campamentos 2018. Informe final. Santiago, Chile: Techo Chile.

De Genova, N., Mezzadra, S., \& Pickles, J. (Eds.). (2015). New Keywords: Migration and Borders. Cultural Studies, 29(1), 55-87. doi: https://doi.org/10.1080/09502386.2014 .891630 .

Domenech, E. (2015). Inmigración, anarquismo y deportación: La criminalización de los extranjeros uindeseables» en tiempos de las "grandes migraciones». REMHU - Rev. Interdiscip. Mobil. Hum., XXIII (45), 169-196. doi: https://doi.org/10.1590/1980- 
8585250319880004509

(2020). La "política de la hostilidad" en Argentina: Detención, expulsión y rechazo en frontera. Estudios fronterizos, 21 (e057). doi: https://doi.org/10.21670/ ref.2015057

Domenech, E., \& Boito, M. E. (2019). «Luchas Migrantes» en Sudamérica: Reflexiones críticas desde la mirada de la autonomía de las migraciones. En: B. Cordero, S. Mezzadra, \& A. Varela Huerta; América Latina en movimiento. Migraciones, límites a la movilidad y sus desbordamientos (pp. 159-190). México, D.F., Madrid y Buenos Aires: UAM, Traficantes de Sueños y Tinta Limón.

Durán Migliardi, C., \& Thayer Correa, E. (2020). Ciudadanía precaria: Hacia una definición conceptual para la caracterización de los procesos migratorios contemporáneos. Revista Republicana, 28, 97-117. doi: http://dx.doi.org/10.21017/Rev. Repub.2020.v28.a78

Finn, V. (2020). Migrant Voting: Here, There, in Both Countries, or Nowhere. Citizenship Studies, 24 (6), 730-750. doi: https://doi.org/10.1080/13621025.2020.1745154

Foucault, M. (2008). El nacimiento de la biopolítica. México, D.F.: Fondo de Cultura Económica.

Franzé, J. (2010). La política como proceso de subjetivación: Un estudio de caso sobre los inmigrantes latinoamericanos en Madrid. En R. de la Fuente Fernández (Ed.), Migración y política: Latinoamericanos en la Comunidad de Madrid (pp. 83-102). Madrid, España: Trama.

Franzoni, J., \& Rosas, M. L. (2006). Migración internacional y prácticas políticas transnacionales: Agentes de cambio en dos comunidades rurales. Estudios Sociológicos, 24 (70), 221-241. doi: https://doi.org/10.24201/es.2006v24n70.386

Garrido Muñoz de Arenillas, R., \& Cubero Pajares, A. (2019). La participación socio-política de las mujeres negras africanas en Sevilla (España). Odisea. Revista de Estudios Migratorios, 6.

Gil Araujo, S., \& Rosas, C. (Julio de 2019). La acción colectiva de las mujeres migrantes como práctica de ciudadanía. Apuntes conceptuales y avances de investigación en el AMBA [Ponencia]. XIV Jornadas Nacionales de Historia de las Mujeres y IX Congreso Iberoamericano de Estudios de Género, Mar del Plata, Argentina.

Jensen, M. F., \& Perret, G. (2013). Una aproximación al estudio de la participación política de la migración chilena residente en Buenos Aires: Luchas por el reconocimiento y disputas por derechos. Temas de Antropología y Migración, 5, 70-90.

Luque, J. C. (2007). Asociaciones políticas de inmigrantes pervanos y la "Lima Chica" en Santiago de Chile. Migraciones Internacionales, 4(2), Article 2, 121-150. doi: https://doi.org/10.17428/rmi.v4i13.1169

Martínez Bonora, V. (2012). Procesos de subjetivación política en la población inmigrante de la ciudad de Buenos Aires (Enfoques de derecho y ciudadanía). Laboratorio de Políticas Públicas. Buenos Aires, Argentina.

Mezzadra, S. (2005). Derecho de fuga. Migraciones, ciudadanía y globalización. Madrid, España: Traficantes de Sueños.

(2012). Capitalismo, migraciones y luchas sociales. La mirada de la autonomía. Nueva Sociedad, 237, 159-178.

Mezzadra, S., \& Neilson, B. (2016). La frontera como método. O la multiplicación del trabajo. Buenos Aires, Argentina: Tinta Limón.

Morice, A. (2007). El difícil reconocimiento de los sin papeles en Francia. Entre tentación individualista y movilización colectiva. En L. Suárez-Navaz (Ed.), Las luchas de los sin papeles y la extensión de la ciudadanía. Perspectivas críticas desde Europa y Estados Unidos (pp. 39-71). Madrid, España: Traficantes de Sueños.

Pavez, J. (2016). Afecciones afrocolombianas. Transnacionalización y racialización del mercado del sexo en las ciudades mineras del norte de Chile. Latin American Research Review, 51 (2), 24-45. doi: https://doi.org/10.1353/lar.2016.0021

Perissinotti, M. V. (2016). Un lugar donde vivir. Las luchas migrantes por el acceso al espacio urbano en la ciudad de Córdoba (Argentina). REMHU - Rev. Interdiscip. Mobil. Hum., XXIV(47), 59-76. doi: https://doi.org/10.1590/198085852503880004705

Perrig, S., \& Gudiño, P. (2008). Cuerpos exceptuados. La trasgresión de lo binario y el devenir de nuevas prácticas. Revista de Ciencias Sociales, IV(122), 39-48.

Rancière, J. (2006). Política, policía, democracia. Santiago, Chile: LOM.

Sayad, A. (1998). A Imigração ou os Paradoxos da Alteridades. São Paulo, Brasil: 
Editora da Universidade de São Paulo.

(2010). Migración y pensamiento de Estado. En La doble ausencia. De las ilusiones del emigrado a los padecimientos del inmigrado (pp. 385-404). Barcelona, España: Anthropos.

Schmeisser, C. (2019). La funa. Aspectos jurídicos y sociales [Memoria para optar al grado de Licenciada en Ciencias Jurídicas y Sociales]. Universidad de Chile, Santiago, Chile.

Stang, F. (2009). El migrante unidimensional. El dispositivo jurídico migratorio en la Comunidad Andina de Naciones. En: Domenech, E. (ed.), Migración y política: El Estado interrogado: Procesos actuales en Argentina y Sudamérica (pp. 301-353). Córdoba, Argentina: Universidad Nacional de Córdoba.

Stang, F., Lara, A., \& Andrade, M. (2020). Retórica humanitaria y expulsabilidad: Migrantes haitianos y gobernabilidad migratoria en Chile. Si Somos Americanos. Revista de Estudios Transfronterizos, 20(1), 176-201. doi: https://doi. org/10.4067/S0719-09482020000100176

Stefoni, C., \& Stang, F. (2017). Diagnóstico de la situación migratoria internacional en la Región de Antofagasta. En: Por una región minera diversificada y fraterna con los migrantes. Diagnóstico participativo y propuestas de política migratoria y de empleo para las ciudades de Antofagasta y Calama. Santiago, Chile: Ariadna.

Suárez Navaz, L. (2007). Introducción. La lucha de los sin papeles. Anomalías democráticas y la (imparable) extensión de la ciudadanía. En: L. Suárez Navaz, R. Macià Pareja, Á. Moreno García, A. Morice, Z. Hellgren, B. Laubenthal, S. B. Coutin, A. Varela Huerta, \& P. Arbide, Las luchas de los sin papeles y la extensión de la ciudadanía. Perspectivas críticas desde Europa y Estados Unidos. Madrid, España: Traficantes de Sueños.

Suárez Navaz, L., Macià Pareja, R., Moreno García, Á., Morice, A., Hellgren, Z., Laubenthal, B., Coutin, S. B., Varela Huerta, A., \& Arbide, P. (2007). Las luchas de los sin papeles y la extensión de la ciudadanía. Perspectivas críticas desde Europa y Estados Unidos. Madrid, España: Traficantes de Sueños.

Thayer, E. (2020). Expulsados y expulsables: Precarización selectiva en la política de frontera (N. ${ }^{4}$; Observatorio de Política Migratoria). UCSH y UChile.

Varela Huerta, A. (2013). Por el derecho a permanecer y a pertenecer. Una sociología de la lucha de migrantes. Madrid, España: Traficantes de Sueños.

(2015). "Luchas migrantes": Un nuevo campo de estudio para la sociología de los disensos. Andamio, $12(28), 145-170$.

Velasco, J. C. (2016). El azar de las fronteras. Políticas migratorias, ciudadanía y justicia. México, D.F.: Fondo de Cultura Económica.

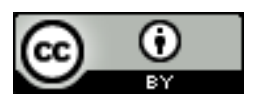

Este es un artículo de acceso abierto bajo licencia Creative Commons Reconocimiento 4.0 Internacional 